\title{
Clinical outcomes of an endoscopic transclival and transpetrosal approach for primary skull base malignancies involving the clivus
}

\author{
*Yong Hwy Kim, MD, ${ }^{1}$ Chiman Jeon, MD, ${ }^{2}$ Young-Bem Se, MD, ${ }^{1}$ Sang Duk Hong, MD, ${ }^{3}$ \\ Ho Jun Seol, MD, PhD, ${ }^{2}$ Jung-II Lee, MD, PhD, ${ }^{2}$ Chul-Kee Park, MD, PhD, ${ }^{1}$ \\ Dong Gyu Kim, MD, PhD, ${ }^{1}$ Hee-Won Jung, MD, PhD, ${ }^{1}$ Doo Hee Han, MD, PhD, ${ }^{4}$ \\ Do-Hyun Nam, MD, PhD, ${ }^{2}$ and Doo-Sik Kong, MD, PhD²
}

\begin{abstract}
Departments of ${ }^{1}$ Neurosurgery and ${ }^{4}$ Otorhinolaryngology-Head and Neck Surgery, Seoul National University Hospital, Seoul National University College of Medicine; and Departments of ${ }^{2}$ Neurosurgery and ${ }^{3}$ Otorhinolaryngology-Head and Neck Surgery, Samsung Medical Center, Sungkyunkwan University School of Medicine, Seoul, Republic of Korea
\end{abstract}

\begin{abstract}
OBJECTIVE The endoscopic endonasal approach for treating primary skull base malignancies involving the clivus is a formidable task. The authors hypothesized that tumor involvement of nearby critical anatomical structures creates hurdles to endoscopic gross-total resection (GTR). The aim of this study was to retrospectively review the clinical outcomes of patients who underwent an endoscopic endonasal approach to treat primary malignancies involving the clivus and to analyze prognostic factors for GTR.

METHODS Between January 2009 and November 2015, 42 patients underwent the endoscopic endonasal approach for resection of primary skull base malignancies involving the clivus at 2 independent institutions. Clinical data; tumor locations within the clivus; and anatomical involvement of the cavernous or paraclival internal carotid artery, cisternal trigeminal nerve, hypoglossal canal, and dura mater were investigated to assess the extent of resection. Possible prognostic factors affecting GTR were also analyzed.

RESULTS Of the 42 patients, 37 were diagnosed with chordomas and 5 were diagnosed with chondrosarcomas. The mean ( \pm SD) preoperative tumor volume was $25.2 \pm 30.5 \mathrm{~cm}^{3}$ (range $\left.0.8-166.7 \mathrm{~cm}^{3}\right)$. GTR was achieved in 28 patients $(66.7 \%)$ and subtotal resection in 14 patients (33.3\%). All tumors were classified as upper $(n=17)$, middle $(n=17)$, or lower $(n=8)$ clival tumors based on clival involvement, and as central $(24$ [57.1\%]) or paramedian (18 [42.9\%]) based on laterality of the tumor. Univariate analysis identified the tumor laterality $(\mathrm{OR} 6.25,95 \% \mathrm{Cl} 1.51-25.86 ; p=0.011)$ as significantly predictive of GTR. In addition, the laterality of the tumor was found to be a statistically significant predictor in multivariate analysis (OR 41.16, 95\% Cl 1.12-1512.65; $p=0.043$ ).
\end{abstract}

CONCLUSIONS An endoscopic endonasal approach can provide favorable clinical and surgical outcomes. However, the tumor laterality should be considered as a potential obstacle to total removal.

https://thejns.org/doi/abs/10.3171/2016.12.JNS161920

KEY WORDS skull base malignancy; chordoma; chondrosarcoma; endoscopic endonasal approach; clivus; tumor laterality; pituitary surgery

$\mathrm{P}$ RIMARY representative malignancies involving the clivus include chordoma and chondrosarcoma, which account for less than $1 \%$ of intracranial neoplasms. These tumors commonly exhibit locally aggressive behavior and midline presentation..$^{15,21,22,27,31,33}$ They most commonly present as sixth cranial nerve $(\mathrm{CN})$ palsy followed by visual field deficits, decreased visual acuity, extraocular motility disorders, and lower $\mathrm{CN}$ palsy., ${ }^{1,6,10}$ Clinical manifestations vary depending on where the tumor is located in the clivus. Tumors in the lower clivus present with lower nerve palsies (CN IX-XII), whereas tumors in the midclivus (CN VI) often result in diplopia

ABBREVIATIONS CN = cranial nerve; GTR = gross-total resection; ICA = internal carotid artery; STR = subtotal resection SUBMITTED July 29, 2016. ACCEPTED December 9, 2016. INCLUDE WHEN CITING Published online June 2, 2017; DOI: 10.3171/2016.12.JNS161920.

* Drs. Y. H. Kim and C. Jeon contributed equally to this work. 
(the most common finding), and chordomas in the upper clivus present with deteriorating visual acuity (CN II) and CN III palsy. ${ }^{6,14,26}$

Maximal safe resection followed by aggressive highdose radiation therapy has been recommended as the treatment of choice. , $14,18,19,32$ However, the resection of primary skull base malignancies involving the clivus remains a challenging task for neurosurgeons because of the anatomical complexity and the proximity to critical neurovascular structures, including $\mathrm{CNs}$, the internal carotid artery (ICA), and the brainstem. Therefore, resection of clival tumors carries a risk of postoperative morbidity. ${ }^{13,15,16,24,28,31}$

The anatomical location of the tumor, which is ventral to the brainstem and invades the cavernous sinus, makes it difficult to approach and often prohibits total removal. ${ }^{17,28,31}$ Regardless of the extent of resection, the high probability of local recurrence makes these tumors more difficult to control. Therefore, management often requires a multidisciplinary team approach involving otolaryngology, radiation oncology, endocrinology, ophthalmology, and rehabilitation. . $^{16,17,31}$

Endoscopic endonasal approaches have gained popularity in the last decade due to their minimally invasive trajectories to the mid- and paramedian skull base..$^{5,8,11}$, 12,20 High-definition endoscopic techniques provide accurate anatomical landmarks, resulting in access to the skull base; in addition, these techniques have improved the surgical outcomes of gross-total resection (GTR), with decreased postoperative morbidity. ${ }^{9,16,28,31}$ However, despite the recent development of the endoscopic approach, some hurdles to the complete removal of tumors involving the clivus remain. In particular, an infiltrating tumor surrounding the ICA often precludes complete resection.

Lesions of the lower clivus pose a similar dilemma in that complete bony resection can lead to hypoglossal nerve injury or occipital cervical instability. ${ }^{31}$ Thick adhesion of the tumor capsule to the brainstem or surrounding vascular structures can be another obstacle to total resection. Lateral extension of a clival tumor across the trigeminal nerve presents another hurdle. Thus, preoperative assessment of the critical anatomical structures involved is essential for successful tumor resection without morbidities.

To our knowledge, few studies have investigated preoperative radiological findings to predict GTR by endoscopic surgery for primary skull base malignancies involving the clivus. We hypothesized that tumor involvement of specific anatomical structures creates hurdles to endoscopic GTR. In this study, we reviewed our experience with endoscopic endonasal surgery for primary malignancies involving the clivus at 2 independent institutions and analyzed possible prognostic factors for GTR.

\section{Methods}

With approval from the institutional review boards, we retrospectively reviewed the endoscopic endonasal surgery registry from both Samsung Medical Center and Seoul National University Hospital between January 2009 and November 2015. We identified 42 patients who underwent endoscopic endonasal resection of clival chordomas and chondrosarcomas during this period. One specialized endoscopic neurosurgeon (Y.H.K.) performed endoscopic endonasal surgery at Seoul National University Hospital, and an endoscopic skull base team comprising 2 neurosurgeons (D.S.K. and D.H.N.) and an otolaryngologist (S.D.H.) was responsible for endoscopic endonasal surgery at Samsung Medical Center. All 3 neurosurgeons had comparable surgical experience with a similar training period, because endoscopic endonasal surgery was first introduced in Korea. The otolaryngologist had less experience with endoscopic skull base surgery.

\section{Preoperative Evaluation}

Before surgery, all patients underwent T1- or T2weighted and Gd-enhanced T1-weighted MRI; all patients also had follow-up postoperative MRI. The preoperative tumor volume was measured radiographically with 3D Slicer (http://www.slicer.org/). On the preoperative radiological evaluation, clival involvement (from cranial to caudal in the sagittal plane) on the upper, middle, and lower third of the clivus was assessed. The upper third spanned from the posterior clinoid process to the petrous apex. The middle third extended from the petrous apex to the jugular foramen. The lower third ranged from the jugular foramen to the odontoid body (Fig. 1).

To evaluate the laterality of the tumor, we defined surrounding critical anatomical structures as a lateral boundary. In the axial imaging plane, the anatomical structures defining the laterality of the tumor included the cavernous ICA, paraclival ICA, intradural cisternal component of the trigeminal nerve pathway, and hypoglossal canal at the lower clivus. Tumors within the bilateral tangent planes composed of these anatomical structures were regarded as midline tumors (central tumors), whereas tumors involving or crossing these boundaries were classified as laterally extended tumors (paramedian tumors) (Fig. 2). Before surgery, we assessed the extent of bony involvement of the tumor in all cases. In our series, no tumors required resection of the bilateral condyles or developed atlantooccipital ligamental instability.

\section{Endoscopic Transclival Approach}

All patients underwent endoscopic endonasal transclival surgery under the guidance of neuronavigation. While under general anesthesia, patients were placed supine with slight extension of the neck, enabling easier access to the lesion. Three- or 4-hand binostril endoscopic endonasal surgery was performed. Before accessing the clival tumor, a unilateral or bilateral nasoseptal mucosal flap was designed and prepared. During tumor removal, a direct $0^{\circ}$ endoscope (Karl Storz Co.) was introduced first, and a $30^{\circ}$ or $45^{\circ}$ endoscope was sometimes used to help "see around the corner."

In tumors adjacent to the dura mater, the peel-off technique was used with the outer layer of the dura to completely obliterate the tumor, leaving the inner layer of the dura as the last barrier to the brainstem. For intradural tumors, all layers of dura were removed and replaced with autologous fascia lata. When removing tumors adjacent to the paraclival or cavernous ICA, intraoperative Doppler ultrasonography was used to accurately locate the ICA. To 

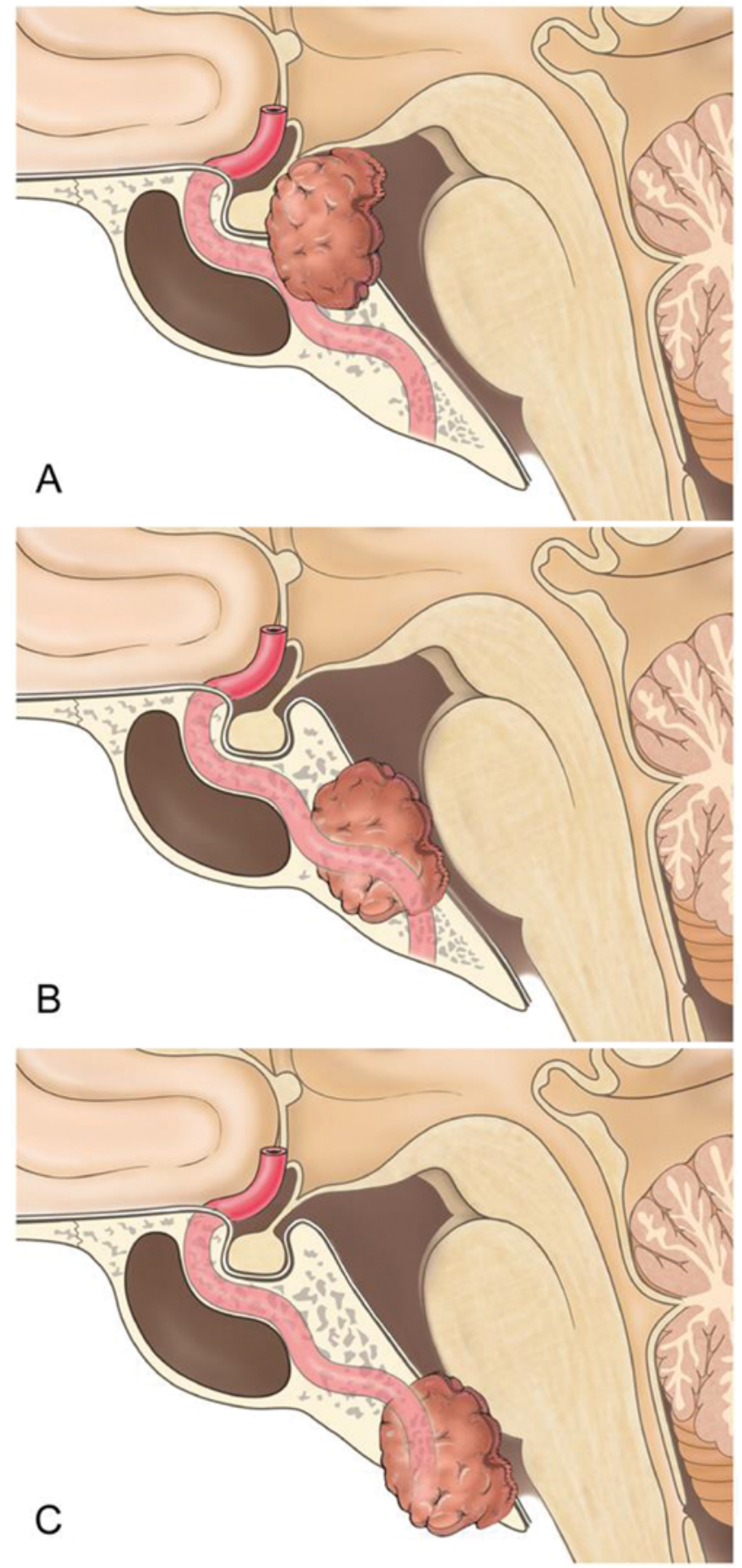

FIG. 1. Proposed sagittal classification of clival tumors involving the upper clivus (A), middle clivus (B), and lower clivus (C). Copyright Samsung Medical Center, Sungkyunkwan University. Published with permission. Figure is available in color online only.

effectively remove the tumor, a rigid or malleable ringcurette was preferred for soft-consistency tumors, whereas endoscopic dedicated ultrasonic cavitation aspirators (Sonoca, Söring $\mathrm{GmbH}$ ) were used for harder tumors.

\section{Endoscopic Transpterygoid Approach}

When the tumor extended from the clivus into the petrous apex or outside of the paraclival ICA, an endoscopic transpterygoid approach was used. An endoscopic transpterygoid approach combined with a transclival approach was performed for paramedian tumors that extended laterally on the preoperative MR image, whereas an endoscopic transclival approach alone was performed for central tumors that were limited to the clivus. Careful preoperative planning of the corridor could help with GTR. To approach this area, anatomical landmarks such as the vidian canal, foramen rotundum, and palatovaginal canal were carefully identified. The transpterygoid approach could be tailored to the target area. The vidian nerve was dissected to approach the infrapetrous area, and the base of the pterygoid process was completely or partially removed to access the lateral recess of the sphenoid sinus, infratemporal fossa, lateral cavernous sinus, or pterygopalatine fossa.

\section{Reconstruction of Skull Base Defects}

After the tumor was removed, autologous fascia lata was applied to the dura as an in-lay or on-lay graft, and a fibrin sealant patch (TachoSil) was attached to the dural margin. Finally, a nasoseptal flap was used to cover the dural defect. In cases without a dural defect, the nasoseptal flap was applied to cover the exposed ICA or was repositioned over the original septum. For patients with intraoperative CSF leaks, lumbar drainage of CSF was sustained for 3-5 days.

\section{Postoperative Evaluation}

The extent of resection was evaluated with postoperative Gd-enhanced MR images by 2 independent radiologists at Samsung Medical Center and Seoul National University Hospital and categorized as GTR, subtotal resection (STR; $\geq 95 \%$ tumor removal), or partial resection $(<95 \%$ tumor removal). GTR was defined as no visible contrast-enhancing mass. Regrowth of a suspicious enhancing mass on follow-up MR images was regarded as recurrence. Intradural/extradural involvement was also radiographically evaluated using preoperative MR images and operation records.

\section{Statistical Analysis}

Descriptive statistics were used to analyze patient demographic data, clinical presentation, tumor characteristics, tumor location, and surgical outcomes. A Student t-test was applied for continuous variables; a $\chi^{2}$ test was used for categorical variables. Univariate and multivariate logistic regression analyses were used to assess the prognostic factors affecting GTR. Differences were considered statistically significant at a $p$ value $<0.05$. Statistical analyses were performed using $\mathrm{R}$ version 3.0.1 (http:// www.R-project.org/).

\section{Ethics Statement}

This retrospective study was approved by the institutional review boards of Samsung Medical Center and Seoul National University Hospital; the informed consent requirement was waived. 


\section{Results}

\section{Clinical Characteristics}

Between January 2009 and November 2015, 42 patients underwent endoscopic endonasal transclival resections. Twelve patients were female and 30 were male. The mean age at the time of diagnosis was 48.7 years (range $10-72$ years). Of the 42 patients, 34 patients (81.0\%) presented with newly diagnosed primary clival tumors, and 8 patients $(19.0 \%)$ had recurrent tumors (previously treated) (Table 1). The mean $( \pm \mathrm{SD})$ preoperative tumor volume was $25.2 \pm 30.5 \mathrm{~cm}^{3}$, ranging from 0.8 to 166.7 $\mathrm{cm}^{3}$. Nineteen patients $(45.2 \%)$ had intradural involvement. Clinical manifestations included $\mathrm{CN}$ deficit $(\mathrm{n}=$ $33)$, headache $(n=7)$, nasal obstruction $(n=3)$, and visual field defects $(n=2)$. CN VI palsy was the most common $\mathrm{CN}$ deficit $(\mathrm{n}=20,60.6 \%)$. Clival tumors were incidentally found in 4 patients (Table 2).

\section{Preoperative Classification Based on Sagittal Location and Laterality of the Tumor}

The location of clival involvement (from cranial to caudal) in the sagittal plane was classified as upper third $(\mathrm{n}=17,40.5 \%)$, middle third $(\mathrm{n}=17,40.5 \%)$, and lower third ( $\mathrm{n}=8,19.0 \%)$. Among 17 cases involving the upper clivus, 10 extended into the dorsum sellae (Fig. 1). The laterality of the tumor was determined by using surrounding critical structures such as the cavernous ICA, paraclival ICA, intradural cisternal component of the trigeminal nerve pathway, and hypoglossal canal. Tumors within the bilateral tangent plane comprising these anatomical structures were regarded as midline tumors (central tumors) $(n=24,57.1 \%)$, and tumors involving or crossing these boundaries were classified as laterally extended tumors (paramedian tumors) in the axial plane (n $=18,42.9 \%)($ Fig. 2$)$.

\section{Clinical Outcomes}

A transclival endoscopic endonasal approach in combination with a transcavernous approach was achieved in 38 patients $(90.5 \%)$, followed by a combined transpterygoid approach in 3 patients (7.1\%). A transodontoid approach was used in only 1 patient (Table 3). Histopathological examination demonstrated 37 clival chordomas and 5 clival chondrosarcomas. Overall, GTR was achieved in 28 patients $(66.7 \%)$ and STR in the remaining 14 patients (33.3\%) (Table 4). Postoperatively, 16 patients underwent proton radiation therapy and 15 underwent Gamma Knife radiosurgery to prevent recurrence. Only 1 patient underwent conventional radiotherapy. During the mean followup of 32.7 months (range 1.0-81.7 months), recurrence occurred in 8 of 42 patients (19.0\%).

Among 20 patients who had preoperative CN VI palsy, the $\mathrm{CN}$ deficit improved after surgery in 11 patients (55.0\%), and only 1 patient developed a new CN VI palsy after surgery. Postoperative CSF leakage occurred in 7 patients $(16.7 \%)$. Among these, 4 patients had intradural invasion of the tumor, and 3 patients had extradural tumors that adhered to the dura. All patients with postoperative CSF leaks underwent reconstructive repair. Only 1 patient had postoperative meningitis.
TABLE 1. Overall distribution of preoperative clinical characteristics

\begin{tabular}{cc}
\hline \multicolumn{1}{c}{ Variable } & No. of Patients $(\%)$ \\
\hline Sex & \\
\hline M & $30(71.4)$ \\
\hline F & $12(28.6)$ \\
\hline Tumor location, sagittal & $17(40.5)$ \\
\hline Upper clivus & $17(40.5)$ \\
\hline Middle clivus & $8(19.0)$ \\
\hline Lower clivus & $24(57.1)$ \\
\hline Tumor location, axial & $18(42.9)$ \\
\hline Central & \\
\hline Paramedian & $23(54.8)$ \\
\hline Dural invasion & $19(45.2)$ \\
\hline Extradural & \\
\hline Intradural & $34(81.0)$ \\
\hline Previous treatment & $8(19.0)$ \\
\hline No &
\end{tabular}

\section{Analysis of Prognostic Factors That Predict GTR}

Laterality of the tumor was statistically significant between the GTR and STR groups ( $\mathrm{p}=0.008)$ (Table 5). No statistical significance was observed for age $(p=0.543)$, sex $(p=0.147)$, histology $(p=0.736)$, clival involvement in the sagittal plane $(p=0.347)$, dural invasion $(p=0.192)$, or institution $(p=0.661)$ between the GTR and STR groups. However, there was a decreasing tendency for achievement of GTR in patients with high tumor volume and previous treatment, although the differences were not statistically significant ( $\mathrm{p}=0.079$ and 0.052 , respectively). The STR group tended to have a larger preoperative tumor volume than the GTR group (40.8 vs $17.3 \mathrm{~cm}^{3} ; \mathrm{p}=0.079$ ). In addition, the recurrent tumor group was more likely to have

TABLE 2. Clinical presentation of patients

\begin{tabular}{cc}
\hline Signs \& Symptoms & No. of Patients \\
\hline CN deficits & 33 \\
\hline CN III & 2 \\
\hline CN IV & 1 \\
\hline CN V & 1 \\
\hline CN VI & 20 \\
\hline CN VII & 2 \\
\hline CN IX & 3 \\
\hline CN X & 3 \\
\hline CN XII & 1 \\
\hline Headache & 7 \\
\hline Nasal obstruction & 3 \\
\hline Blurred vision & 1 \\
\hline Visual field defect & 2 \\
\hline Seizure & 1 \\
\hline Incidentally found & 4 \\
\hline
\end{tabular}




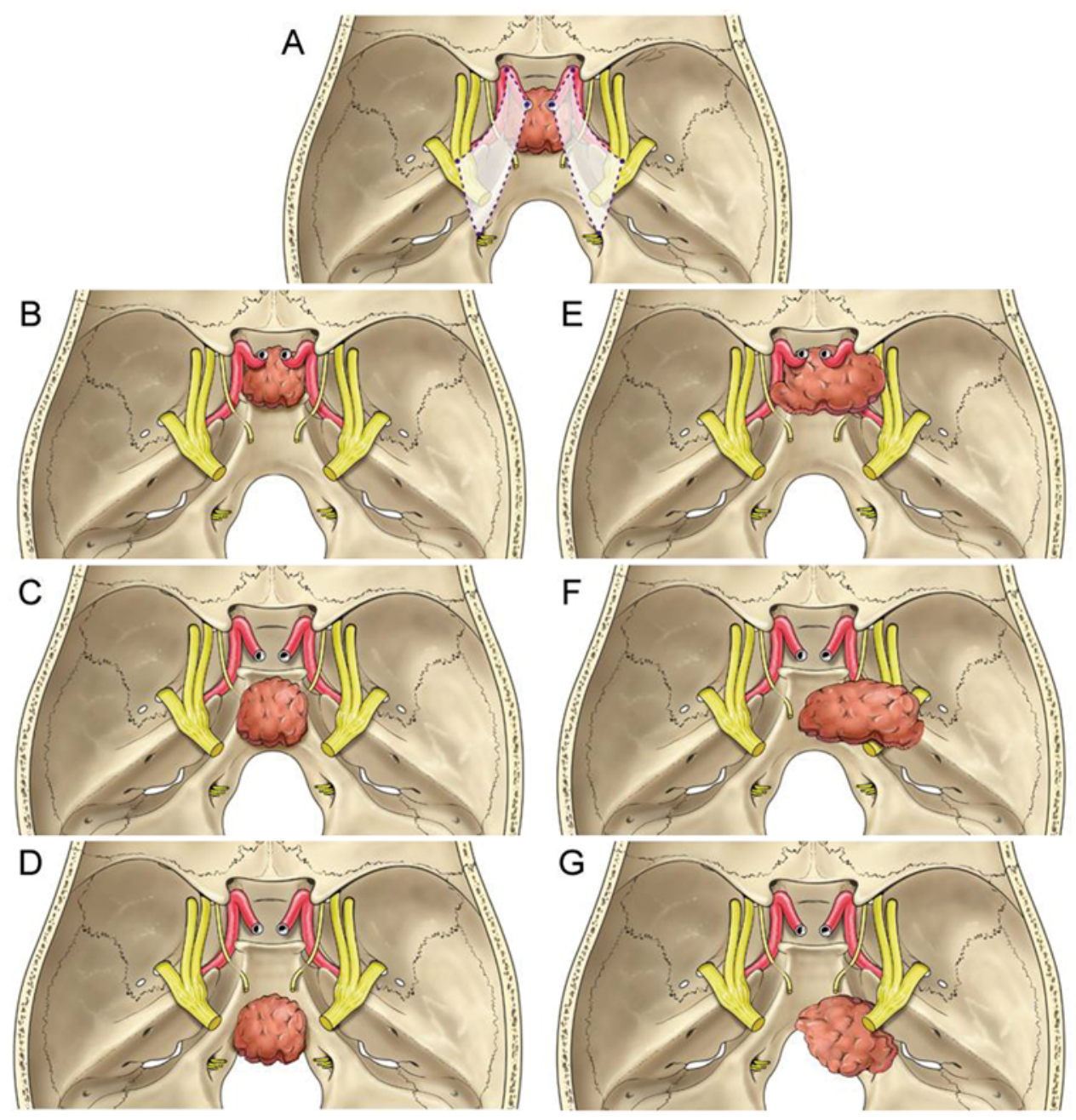

FIG. 2. The dotted lines represent tangent planes that define the laterality of the clival tumors. Each plane includes the cavernous ICA, paraclival ICA, cisternal portion of the trigeminal nerve, and hypoglossal canal (A). Tumors within the bilateral tangential planes were regarded as midline tumors (central), whereas those involving or crossing the planes were regarded as laterally extended tumors (paramedian). An axial classification was proposed for those located within or extending beyond the paraclival ICA (B and E), cisternal portion of the trigeminal nerve ( $\mathbf{C}$ and $\mathbf{F})$, and hypoglossal canal ( $\mathbf{D}$ and $\mathbf{G})$. Copyright Samsung Medical Center, Sungkyunkwan University. Published with permission. Figure is available in color online only.

STR than the primary tumor group $(\mathrm{p}=0.052)$. Univariate analysis demonstrated that central tumor (without laterality) was the only significant predictor of GTR (OR 6.25, $95 \%$ CI $1.51-25.86 ; \mathrm{p}=0.011)$. Although not statistically significant, preoperative tumor volume $(\mathrm{p}=0.059)$ and no previous treatment $(\mathrm{p}=0.064)$ tended to be associated with GTR. In addition, a central tumor (without laterality) was found to be a statistically significant predictor of GTR in multivariate analysis (OR 41.16, 95\% CI 1.12-1512.65; $\mathrm{p}=0.043)($ Table 6).

\section{Discussion}

Chordomas and chondrosarcomas from the clivus are rare tumors, accounting for only $0.2 \%$ of all intracranial neoplasms. Clival chordomas are slow-growing, locally invasive tumors that originate from the notochord remnant involving the clivus at the midline, ${ }^{20,25}$ whereas clival chondrosarcomas arise from chondrocytes within endochon- dral cartilage at the paramedian skull base. ${ }^{3,4,11}$ They are histologically malignant and locally aggressive. ${ }^{1,21,27}$ Both types of extraaxial tumors tend to infiltrate the skull base to a variable extent and can invade surrounding soft tissue adjacent to major vessels and CNs. ${ }^{7,14,21,26}$ Due to their invasiveness and proximity to critical neurovascular structures, GTR of skull base malignancies involving the clivus is not always possible; therefore, it is frequently accompanied by adjuvant treatment, such as proton radiation therapy. ${ }^{6,7,20}$

TABLE 3. Operative approaches with transclival endoscopic endonasal approach

\begin{tabular}{cc}
\hline Op Approach & No. of Patients \\
\hline Transcavernous & 38 \\
\hline Transpterygoid & 3 \\
\hline Transodontoid & 1 \\
\hline
\end{tabular}


TABLE 4. Clinical information for patients treated with endoscopic transclival resection of clival tumors

\begin{tabular}{|c|c|c|c|c|c|c|c|c|c|c|}
\hline Laterality & $\begin{array}{c}\text { Case } \\
\text { No. }\end{array}$ & $\begin{array}{c}\text { Sex/Age } \\
\text { (yrs) }\end{array}$ & Clinical Features & Location & $\begin{array}{c}\text { Vol } \\
\left(\mathrm{cm}^{3}\right)\end{array}$ & Intradural & Histology & Resection & $\begin{array}{l}\text { CSF } \\
\text { Leak }\end{array}$ & $\begin{array}{c}\text { Mean FU } \\
\text { (mos) }\end{array}$ \\
\hline \multirow[t]{24}{*}{ Central* } & 4 & $M / 31$ & Incidentally found & Lower & 29.6 & No & Chordoma & GTR & No & 78.4 \\
\hline & 10 & $M / 56$ & CN VI & Middle & 8 & Yes & Chordoma & GTR & Yes & 32.2 \\
\hline & 12 & $F / 66$ & CN VI & Upper & 18.1 & No & Chordoma & GTR & No & 21.2 \\
\hline & 13 & $\mathrm{M} / 67$ & Incidentally found & Upper & 2.6 & No & Chordoma & GTR & Yes & 20.9 \\
\hline & 15 & $F / 63$ & $\mathrm{HA}$ & Upper & 5.6 & No & Chordoma & GTR & Yes & 19.4 \\
\hline & 16 & $M / 62$ & CN VI & Upper & 2.6 & No & Chordoma & GTR & No & 19.3 \\
\hline & 17 & $\mathrm{~F} / 64$ & $\mathrm{HA}$ & Lower & 0.8 & No & Chordoma & GTR & No & 14.6 \\
\hline & 19 & $\mathrm{M} / 60$ & Incidentally found & Middle & 15.7 & No & Chordoma & GTR & Yes & 14.4 \\
\hline & 20 & $M / 53$ & CN VI & Upper & 5.3 & Yes & Chordoma & GTR & No & 13.5 \\
\hline & 21 & $M / 63$ & CNs IX \& X & Middle & 12.4 & Yes & Chordoma & GTR & No & 3.9 \\
\hline & 23 & $\mathrm{~F} / 39$ & $\mathrm{HA}$ & Lower & 11.2 & No & Chordoma & GTR & No & 1.0 \\
\hline & 24 & $M / 34$ & Incidentally found & Lower & 10.8 & No & Chordoma & GTR & No & 72.8 \\
\hline & 30 & $\mathrm{~F} / 50$ & CNs III, IV, \& VI & Middle & 35.7 & Yes & Chordoma & GTR & No & 44.1 \\
\hline & 31 & $M / 18$ & NO & Lower & 56.5 & No & Chordoma & GTR & No & 38.2 \\
\hline & 33 & $M / 41$ & CN VI & Middle & 4.1 & Yes & Chordoma & GTR & No & 30.5 \\
\hline & 34 & $M / 34$ & Incidentally found & Middle & 19.7 & Yes & Chordoma & GTR & No & 29.1 \\
\hline & 35 & $F / 35$ & CN VI & Middle & 5.2 & No & Chordoma & GTR & No & 28.8 \\
\hline & 37 & $\mathrm{M} / 71$ & CN VI & Upper & 10 & Yes & Chordoma & GTR & No & 26.9 \\
\hline & 39 & $\mathrm{M} / 19$ & CN VI & Upper & 52.3 & Yes & Chordoma & GTR & Yes & 11.1 \\
\hline & 41 & $M / 20$ & CN VI & Middle & 8.4 & Yes & Chondrosarcoma & GTR & No & 2.5 \\
\hline & 1 & $\mathrm{~F} / 53$ & CN VI & Upper & 13.6 & Yes & Chordoma & STR & No & 81.7 \\
\hline & 6 & $\mathrm{~F} / 10$ & CN VI & Middle & 49.6 & Yes & Chordoma & STR & No & 65.5 \\
\hline & 7 & $\mathrm{M} / 48$ & CN VI & Middle & 2.6 & Yes & Chordoma & STR & Yes & 3.4 \\
\hline & 11 & $M / 33$ & $\mathrm{HA}$ & Middle & 21.9 & Yes & Chordoma & STR & No & 26.1 \\
\hline \multirow[t]{18}{*}{ Paramedian† } & 2 & $\mathrm{~F} / 54$ & BV & Upper & 10 & No & Chordoma & GTR & No & 78.9 \\
\hline & 3 & $\mathrm{~F} / 54$ & CN VI & Upper & 42 & No & Chordoma & GTR & No & 30.1 \\
\hline & 5 & $\mathrm{M} / 67$ & HA, VFD & Upper & 9.6 & No & Chordoma & GTR & No & 75.3 \\
\hline & 18 & $\mathrm{M} / 72$ & CN V & Middle & 13.2 & No & Chordoma & GTR & No & 14.5 \\
\hline & 22 & $\mathrm{~F} / 56$ & CN VI & Middle & 22.8 & Yes & Chondrosarcoma & GTR & No & 1.3 \\
\hline & 26 & $M / 54$ & CNs IX \& X & Lower & 43.4 & No & Chordoma & GTR & No & 60.4 \\
\hline & 38 & $M / 22$ & $\mathrm{CN} \mathrm{VI}$ & Upper & 18.6 & Yes & Chondrosarcoma & GTR & No & 24.6 \\
\hline & 40 & $\mathrm{~F} / 71$ & $\mathrm{CN} \mathrm{VI}$ & Upper & 10.4 & Yes & Chordoma & GTR & No & 9.8 \\
\hline & 8 & $M / 29$ & CNs III \& VII VFD & Middle & 166.7 & No & Chordoma & STR & No & 44.8 \\
\hline & 9 & $\mathrm{M} / 56$ & $\mathrm{HA}$ & Upper & 45.5 & Yes & Chordoma & STR & No & 32.6 \\
\hline & 14 & $\mathrm{M} / 49$ & $\mathrm{HA}$ & Upper & 6.7 & No & Chordoma & STR & No & 19.6 \\
\hline & 25 & $\mathrm{M} / 70$ & CN VII & Middle & 37.2 & Yes & Chordoma & STR & Yes & 69.3 \\
\hline & 27 & $M / 54$ & CNs IX \& X & Lower & 23.4 & No & Chordoma & STR & No & 53.4 \\
\hline & 28 & $\mathrm{M} / 67$ & CN VI & Upper & 23.2 & No & Chordoma & STR & No & 55.9 \\
\hline & 29 & $\mathrm{M} / 67$ & CN VI & Upper & 10 & No & Chordoma & STR & No & 41.5 \\
\hline & 32 & $M / 53$ & Incidentally found & Middle & 16.2 & No & Chondrosarcoma & STR & No & 33.3 \\
\hline & 36 & $M / 36$ & Seizure & Middle & 45 & Yes & Chondrosarcoma & STR & No & 27.0 \\
\hline & 42 & $M / 24$ & CNs VI \& XII & Lower & 110.2 & No & Chordoma & STR & No & 1.5 \\
\hline
\end{tabular}

$\mathrm{BV}=$ blurred vision; $\mathrm{FU}=$ follow-up; $\mathrm{HA}$ = headache; $\mathrm{NO}=$ nasal obstruction; $\mathrm{VFD}=$ visual field defect.

* Tumors within the bilateral tangent planes composed of these anatomical structures were regarded as midline tumors.

$\dagger$ Tumors involving or crossing the planes were classified as laterally extended tumors.

Advanced endoscopic endonasal approaches (such as the transpterygoid procedure, extradural pituitary transposition, petrous apex approach, and far-medial approach) can be used to achieve complete tumor resection. ${ }^{9,30,31}$ En- doscopic endonasal surgery provides a minimal-access corridor that limits surgical exposure to the clivus, thereby obviating the need to retract the brain or to destroy the normal petrous bony portion. ${ }^{8,12,19,31}$ It also provides high 
TABLE 5. Evaluation of factors associated with the extent of tumor resection

\begin{tabular}{|c|c|c|c|}
\hline Variable & GTR & STR & $\mathrm{p}$ Value \\
\hline No. of patients & 28 & 14 & \\
\hline Age in yrs, mean \pm SD & $49.8 \pm 17.2$ & $46.5 \pm 17.6$ & 0.543 \\
\hline Vol in $\mathrm{cm}^{3}$, mean $\pm \mathrm{SD}$ & $17.3 \pm 15.3$ & $40.8 \pm 45.3$ & 0.079 \\
\hline Sex & & & 0.147 \\
\hline M & 18 & 12 & \\
\hline $\mathrm{F}$ & 10 & 2 & \\
\hline Histology & & & 0.736 \\
\hline Chordoma & 25 & 12 & \\
\hline Chondrosarcoma & 3 & 2 & \\
\hline $\begin{array}{l}\text { Clival involvement: } \\
\text { craniocaudal extent }\end{array}$ & & & 0.347 \\
\hline Upper clivus & 12 & 5 & \\
\hline Middle clivus & 10 & 7 & \\
\hline Lower clivus & 6 & 2 & \\
\hline Dural invasion & & & 0.192 \\
\hline Extradural & 16 & 7 & \\
\hline Intradural & 12 & 7 & \\
\hline Tumor laterality & & & $0.008^{*}$ \\
\hline Central & 20 & 4 & \\
\hline Paramedian & 8 & 10 & \\
\hline Treatment history & & & 0.052 \\
\hline No & 25 & 9 & \\
\hline Yes & 3 & 5 & \\
\hline Institution & & & 0.661 \\
\hline SMC & 16 & 7 & \\
\hline SNUH & 12 & 7 & \\
\hline
\end{tabular}

SMC = Samsung Medical Center; SNUH = Seoul National University Hospital. Values are expressed as the number of patients unless indicated otherwise.

* Statistically significant.

magnification and better illumination of the surgical field, maximizing intraoperative visualization of the clivus. In addition, an angled endoscope enables surgeons to widen the operative field without enlarging the surgical corridor. ${ }^{11,12,19}$
Nevertheless, the most challenging hurdle encountered with an endoscopic approach to these tumors is removal of a tumor that invades beyond the ICA. ${ }^{13}$ The GTR rate of clival tumors depends entirely upon the extent of tumor invasion into the surrounding structures, especially the ICA. ${ }^{11-13,16,23,29,32}$ In this study, we found that patients with tumors that invaded the cavernous sinus had worse outcomes than those with tumors that were limited to the clivus. For tumors that invade the cavernous sinus, GTR is difficult to achieve because it carries a lethal risk of ICA injury during tumor manipulation.

When a large tumor involves the cavernous sinus, it creates its own surrounding space, which coincidentally provides surgical working space within the sinus. However, for small tumors, the narrow entrance to the cavernous sinus is usually not sufficient for surgical manipulation, which results in poor visualization of the surgical field. Therefore, more careful and concentric surgical techniques are warranted to completely obliterate cavernous sinus-invading tumors.

In this study, we classified clival tumors according to sagittal location and laterality. To classify sagittal location, we used the traditional classification of the upper, middle, and lower third of the clivus (Fig. 1). In addition, to classify laterality, we drew a tangent plane using the cavernous ICA, paraclival ICA, cisternal portion of the trigeminal nerve, and hypoglossal canal (Fig. 2). Clival chordomas in the upper clivus were most common, and 10 of them extended into the dorsum sellae. Although the GTR rate of clival chordomas and chondrosarcomas in the upper clivus was higher than that of tumors in the middle and lower clivus, the different locations in the sagittal plane did not have a clinically significant difference in the extent of resection.

This result implies that transclival endoscopic endonasal surgery has advantages in covering the whole tumor sagittally from the dorsum sellae to the body of the axis (Fig. 3). In contrast, both univariate and multivariate analyses in this study revealed that tumor laterality was strongly related to the extent of resection. Tumor laterality delimits the extent of resection, thereby minimizing the likelihood of GTR. Thus, endoscopic endonasal surgery has some limitations in its ability to extend the surgical field later-

TABLE 6. Results of univariate and multivariate logistic regression analyses of predictors of GTR of clival tumors

\begin{tabular}{|c|c|c|c|c|c|c|}
\hline \multirow[b]{2}{*}{ Variable } & \multicolumn{3}{|c|}{ Univariate Analysis } & \multicolumn{3}{|c|}{ Multivariate Analysis } \\
\hline & OR & $95 \% \mathrm{Cl}$ & $p$ Value & OR & $95 \% \mathrm{Cl}$ & p Value \\
\hline Age & 1.01 & $0.98-1.05$ & 0.533 & 1.07 & $0.98-1.17$ & 0.162 \\
\hline Vol & 0.97 & $0.933-1.001$ & 0.059 & 0.99 & $0.94-1.05$ & 0.764 \\
\hline Sex, M & 0.30 & $0.06-1.62$ & 0.161 & 0.27 & $0.27-2.66$ & 0.260 \\
\hline Chordoma & 1.39 & $0.20-9.45$ & 0.737 & 28.28 & $0.68-1183.19$ & 0.079 \\
\hline Upper clivus & 0.60 & $0.09-3.89$ & 0.592 & 0.06 & $0.002-1.804$ & 0.104 \\
\hline Middle clivus & 0.29 & $0.04-1.82$ & 0.185 & 0.29 & $0.01-5.99$ & 0.419 \\
\hline Extradural invasion & 1.33 & $0.37-4.83$ & 0.661 & 0.43 & $0.03-5.76$ & 0.520 \\
\hline Central tumor (w/o laterality) & 6.25 & $1.51-25.86$ & $0.011^{*}$ & 41.16 & $1.12-1512.65$ & $0.043^{*}$ \\
\hline No previous treatment & 4.63 & $0.91-23.43$ & 0.064 & 4.13 & $0.53-32.26$ & 0.176 \\
\hline
\end{tabular}

* Statistically significant. 

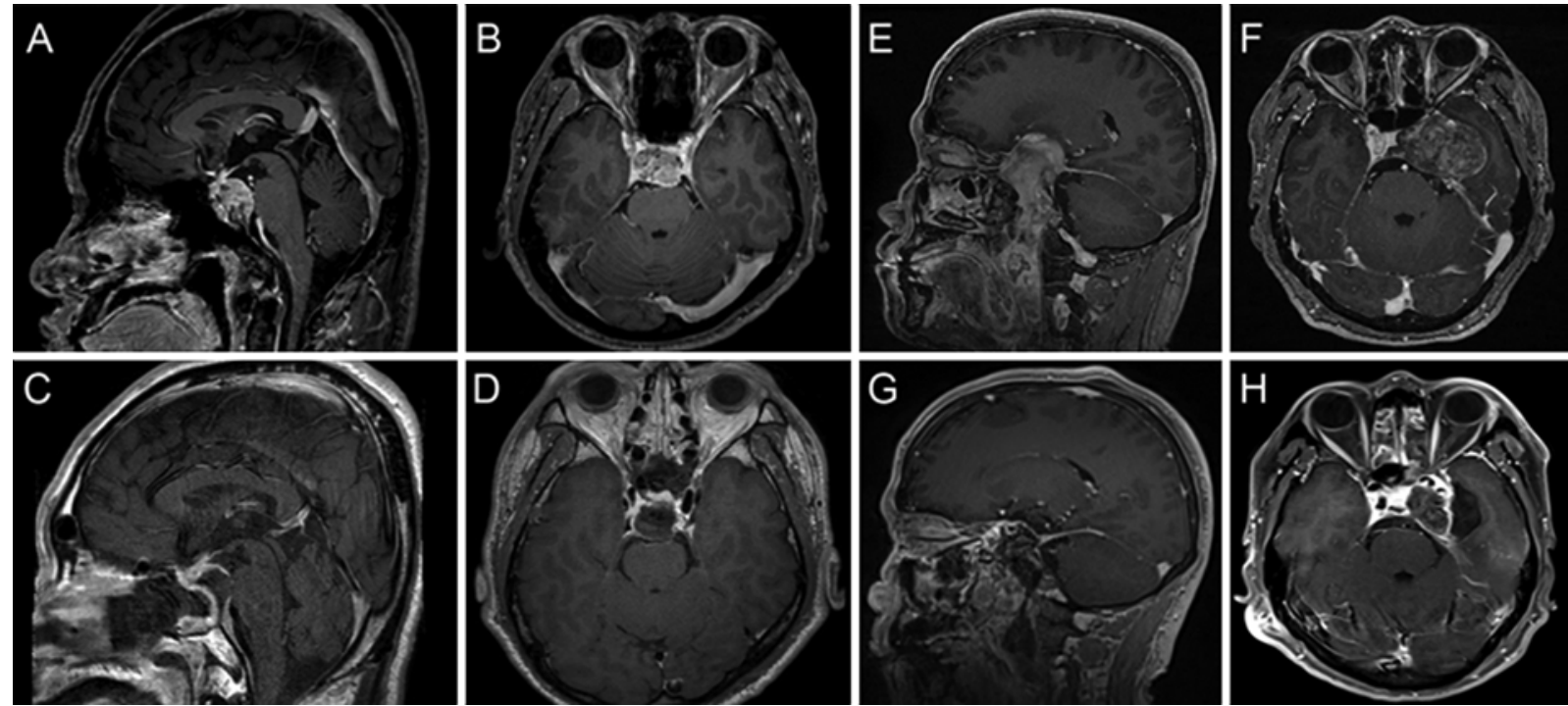

FIG. 3. Preoperative (A, B, E, and F) and postoperative (C, D, G, and H) Gd-enhanced T1-weighted MR scans. Case 20 (A-D): GTR of a centrally located chordoma on the upper clivus in a 53-year-old man with diplopia. Case 36 (E-H): STR of an upper and middle clivus chordoma extending beyond the left paraclival ICA into the left temporal lobe in a 36-year-old man with seizure. The patient developed a CN VI palsy after surgery.

ally, despite advances in the endoscopic transpterygoid approach.

However, a meticulous preoperative evaluation of the laterality of clival tumors is crucial to determining the extent of resection. In addition, this study included 8 recurrent cases. We found that there was no significant difference between primary and recurrent cases, despite a decreasing trend toward GTR in the recurrent cases $(\mathrm{p}=$ $0.064)$. The reason redo surgery had a similar result to resection for primary tumor may be attributable to the relatively high incidence of simple biopsy or partial resection alone without radiotherapy in most of the recurrent cases (6 of 8 cases).

The present study has several limitations. Given the rare incidence of clival chordoma and chondrosarcoma, the sample size in this study was small, and it is difficult to draw definite conclusions. Our data set may not be sufficient to clearly elucidate the relationship between GTR and the factors analyzed in this study, although data were collected from 2 institutions. In addition, our series involved a limited follow-up. Considering the high probability of local recurrence and mortality, a longer follow-up is necessary to perform a detailed analysis of endoscopic endonasal surgery for primary skull base malignancies involving the clivus.

Most clivus-involving tumors are malignant lesions that are not responsive to adjuvant therapy. Therefore, it is required to remove these tumors as totally as possible. In this study, the GTR rate was only $66.7 \%$, which is low, even when considering the difficulty of the surrounding neurovascular complex. Despite the availability of the endoscopic approach for clival tumors, we have to be aware of the potential limitations of this approach.

\section{Conclusions}

Minimally invasive endoscopic endonasal surgery is essential for resection of primary skull base malignancies involving the clivus. Our data suggest that this approach is a safe alternative to conventional transcranial approaches.

\section{Acknowledgments}

We thank Dong-Soo Jang for his work on Figs. 1 and 2. This research was supported by a grant from the Korea Health Technology R\&D Project through the Korea Health Industry Development Institute, funded by the Ministry of Health \& Welfare, Republic of Korea (HI14C3418); grants (NRF-2015M3A9A7029740, NRF2015M3C9A1044522, and NRF-2015M3A9B5053642) from the National Research Foundation, funded by the Ministry of Science, ICT and Future Planning (Korea); and a grant from the Samsung Medical Center.

\section{References}

1. al-Mefty O, Borba LA: Skull base chordomas: a management challenge. J Neurosurg 86:182-189, 1997

2. Amichetti M, Cianchetti M, Amelio D, Enrici RM, Minniti G: Proton therapy in chordoma of the base of the skull: a systematic review. Neurosurg Rev 32:403-416, 2009

3. Awad M, Gogos AJ, Kaye AH: Skull base chondrosarcoma. J Clin Neurosci 24:1-5, 2016

4. Brackmann DE, Teufert KB: Chondrosarcoma of the skull base: long-term follow-up. Otol Neurotol 27:981-991, 2006

5. Cavallo LM, Messina A, Cappabianca P, Esposito F, de Divitiis E, Gardner P, et al: Endoscopic endonasal surgery of the midline skull base: anatomical study and clinical considerations. Neurosurg Focus 19(1):E2, 2005

6. Colli BO, Al-Mefty O: Chordomas of the skull base: followup review and prognostic factors. Neurosurg Focus 10(3):E1, 2001

7. Crockard HA, Steel T, Plowman N, Singh A, Crossman J, Revesz T, et al: A multidisciplinary team approach to skull base chordomas. J Neurosurg 95:175-183, 2001

8. Dehdashti AR, Ganna A, Witterick I, Gentili F: Expanded endoscopic endonasal approach for anterior cranial base and suprasellar lesions: indications and limitations. Neurosurgery 64:677-689, 2009 
9. Fernandez-Miranda JC, Gardner PA, Rastelli MM Jr, PerisCelda M, Koutourousiou M, Peace D, et al: Endoscopic endonasal transcavernous posterior clinoidectomy with interdural pituitary transposition. J Neurosurg 121:91-99, 2014

10. Forsyth PA, Cascino TL, Shaw EG, Scheithauer BW, O'Fallon JR, Dozier JC, et al: Intracranial chordomas: a clinicopathological and prognostic study of 51 cases. J Neurosurg 78:741-747, 1993

11. Frank G, Sciarretta V, Calbucci F, Farneti G, Mazzatenta D, Pasquini E: The endoscopic transnasal transsphenoidal approach for the treatment of cranial base chordomas and chondrosarcomas. Neurosurgery 59:ONS50-ONS57, 2006

12. Fraser JF, Nyquist GG, Moore N, Anand VK, Schwartz TH: Endoscopic endonasal transclival resection of chordomas: operative technique, clinical outcome, and review of the literature. J Neurosurg 112:1061-1069, 2010

13. Gardner PA, Tormenti MJ, Pant H, Fernandez-Miranda JC, Snyderman $\mathrm{CH}$, Horowitz MB: Carotid artery injury during endoscopic endonasal skull base surgery: incidence and outcomes. Neurosurgery 73:ons261-ons270, 2013

14. Gay E, Sekhar LN, Rubinstein E, Wright DC, Sen C, Janecka IP, et al: Chordomas and chondrosarcomas of the cranial base: results and follow-up of 60 patients. Neurosurgery 36:887-897, 1995

15. Guinto G, Guinto-Nishimura Y: Clivus chordomas: role of surgery. World Neurosurg 81:688-689, 2014

16. Hong Jiang W, Ping Zhao S, Hai Xie Z, Zhang H, Zhang J, Yun Xiao J: Endoscopic resection of chordomas in different clival regions. Acta Otolaryngol 129:71-83, 2009

17. Jahangiri A, Chin AT, Wagner JR, Kunwar S, Ames C, Chou $\mathrm{D}$, et al: Factors predicting recurrence after resection of clival chordoma using variable surgical approaches and radiation modalities. Neurosurgery 76:179-186, 2015

18. Jian BJ, Bloch OG, Yang I, Han SJ, Aranda D, Tihan T, et al: Adjuvant radiation therapy and chondroid chordoma subtype are associated with a lower tumor recurrence rate of cranial chordoma. J Neurooncol 98:101-108, 2010

19. Komotar RJ, Starke RM, Raper DM, Anand VK, Schwartz TH: The endoscope-assisted ventral approach compared with open microscope-assisted surgery for clival chordomas. World Neurosurg 76:318-327, 259-262, 2011

20. Koutourousiou M, Gardner PA, Tormenti MJ, Henry SL, Stefko ST, Kassam AB, et al: Endoscopic endonasal approach for resection of cranial base chordomas: outcomes and learning curve. Neurosurgery 71:614-625, 2012

21. Lanzino G, Sekhar LN, Hirsch WL, Sen CN, Pomonis S, Snyderman CH: Chordomas and chondrosarcomas involving the cavernous sinus: review of surgical treatment and outcome in 31 patients. Surg Neurol 40:359-371, 1993

22. McMaster ML, Goldstein AM, Bromley CM, Ishibe N, Parry DM: Chordoma: incidence and survival patterns in the United States, 1973-1995. Cancer Causes Control 12:1-11, 2001

23. Menezes AH, Gantz BJ, Traynelis VC, McCulloch TM: Cranial base chordomas. Clin Neurosurg 44:491-509, 1997

24. Russo VM, Graziano F, Russo A, Albanese E, Ulm AJ: High anterior cervical approach to the clivus and foramen magnum: a microsurgical anatomy study. Neurosurgery 69 (1 Suppl Operative):ons103-ons116, 2011

25. Samii A, Gerganov VM, Herold C, Hayashi N, Naka T, Mirzayan MJ, et al: Chordomas of the skull base: surgical management and outcome. J Neurosurg 107:319-324, 2007

26. Sen C, Triana AI, Berglind N, Godbold J, Shrivastava RK: Clival chordomas: clinical management, results, and complications in 71 patients. J Neurosurg 113:1059-1071, 2010

27. Sen CN, Sekhar LN, Schramm VL, Janecka IP: Chordoma and chondrosarcoma of the cranial base: an 8-year experience. Neurosurgery 25:931-941, 1989

28. Solares CA, Fakhri S, Batra PS, Lee J, Lanza DC: Transnasal endoscopic resection of lesions of the clivus: a preliminary report. Laryngoscope 115:1917-1922, 2005

29. Stippler M, Gardner PA, Snyderman CH, Carrau RL, Prevedello DM, Kassam AB: Endoscopic endonasal approach for clival chordomas. Neurosurgery 64:268-278, 2009

30. Van Gompel JJ, Alikhani P, Tabor MH, van Loveren HR, Agazzi S, Froelich S, et al: Anterior inferior petrosectomy: defining the role of endonasal endoscopic techniques for petrous apex approaches. J Neurosurg 120:1321-1325, 2014

31. Van Gompel JJ, Janus JR: Chordoma and chondrosarcoma. Otolaryngol Clin North Am 48:501-514, 2015

32. Vellutini EA, Balsalobre L, Hermann DR, Stamm AC: The endoscopic endonasal approach for extradural and intradural clivus lesions. World Neurosurg 82 (6 Suppl):S106-S115, 2014

33. Wang K, Wang L, Tian K, Xiao X, Wu Z, Jia G, et al: Surgical resection of upper-middle clivus chordomas via a modified anterior transpetrous approach. Clin Neurol Neurosurg 130:20-25, 2015

\section{Disclosures}

The authors report no conflict of interest concerning the materials or methods used in this study or the findings specified in this paper.

\section{Author Contributions}

Conception and design: Kong, Jeon. Acquisition of data: YH Kim, Jeon, Se. Analysis and interpretation of data: Kong, YH Kim, Jeon. Drafting the article: Jeon. Critically revising the article: all authors. Reviewed submitted version of manuscript: all authors. Approved the final version of the manuscript on behalf of all authors: Kong. Statistical analysis: Jeon. Study supervision: Kong, YH Kim.

\section{Correspondence}

Doo-Sik Kong, Department of Neurosurgery, Samsung Medical Center, Sungkyunkwan University School of Medicine, Irwonro 81, Gangnam-gu, Seoul, 06351, Republic of Korea. email: neurokong@gmail.com. 